Table 1 gives a comparison of our results $\alpha_{1}$ for the 1 s-state with Latter's results ${ }^{4}$ for several $Z$-values.

\begin{tabular}{cccccccccccccc}
\hline$Z$ & 8 & 10 & 13 & 19 & 26 & 29 & 37 & 47 & 57 & 65 & 74 & 82 & 92 \\
\hline (a) & 6.092 & - & 10.536 & 16.022 & 22.546 & 25.365 & 32.939 & 42.485 & 51.971 & 59.800 & 68.498 & 76.250 & 85.965 \\
(b) & 5.897 & 7.680 & 10.260 & 15.962 & 22.455 & 25.404 & 33.048 & 42.672 & 52.347 & 59.785 & 68.348 & 76.722 & 85.769 \\
\hline
\end{tabular}

Table 1. A comparison of our results (b) with Latter's results (a) for the ls-state and several $Z$-values.

Table 2 shows a comparison of our approximate eigenvalues $\alpha_{1}$ for $Z=80$ with the corresponding Hartree eigenvalues for several quantum numbers.

\begin{tabular}{llccccccccc}
\hline States & $1 \mathrm{~s}$ & $2 \mathrm{~s}$ & $2 \mathrm{p}$ & \multicolumn{1}{c}{$3 \mathrm{~s}$} & $3 \mathrm{p}$ & $3 \mathrm{~d}$ & $4 \mathrm{~s}$ & $4 \mathrm{p}$ & $4 \mathrm{~d}$ & $4 \mathrm{f}$ \\
\hline$\alpha_{1}$ Eq. (7) & 74.728 & 30.794 & 30.348 & 15.218 & 14.713 & 13.702 & 7.521 & 7.041 & 6.079 & 4.638 \\
Hartree & 74.48 & 30.41 & 29.87 & 14.76 & 14.19 & 13.08 & 6.87 & 6.34 & 5.27 & 3.09 \\
\hline
\end{tabular}

Table 2. A comparison of our approximate eigenvalues $\alpha_{1}$ given by Eq. (7) for $Z=80$ with the corresponding Hartree-values.

Table 1 and 2 show that the approximate eigenvalues calculated by help of Eq. (7) give reasonable results. In order to obtain more accurate eigenvalues than those given by $\alpha_{1}$ we must solve a determinant of higher order than that in Eq. (6). The corresponding eigenfunc- tions for practical purpose are obtained from Eqs. (2) and (5) by respecting only finite numbers of the coefficients $c_{n-l-1}$ so that the eigenfunctions show the proper numbers of zeroes. Eq. (2) shows that the eigenfunctions have accurate behavior for $r=0$ and $r \rightarrow \infty$.

4 T. TIETZ, Z. Naturforsch. 19 a, 1413 [1964].

\section{Reactivity Indices in Benzotropones}

\section{KLASinc}

Kernforschungszentrum Karlsruhe, Institut f. Strahlenchemie, Karlsruhe, Germany

and Z. Majerski and N. Trinajstić

Institute "Rudjer Bošković", Zagreb, Croatia, Yugoslavia

(Z. Naturforsch. 23 a, 192-194 [1968] ; received 1 November 1967)

The present communication reports a theoretical study of the reactivity indices of tropones fused with a benzene ring; the so-called benzotropones. There are three possible benzotropones: 4,5-benzotropone, 2,3benzotropone, and 3,4-benzotropone, shown in Fig. 1. Several research workers ${ }^{1-9}$ have reported the syntheses and properties of 4,5-benzotropone and 2,3. benzotropone. To our knowledge there is so far no synthesis of 3,4-benzotropone reported in literature. We have investigated these molecules regarding substitution and addition reactions, being interested in predict-

1 J. Thiele and F. G. Falk, Ann. Chem. 347, 112 [1906].

2 J. Thiele and J. Schneider, Ann. Chem. 369, 287 [1909].

3 J. Thiele and E. Weitz, Ann. Chem. 377, 1 [1910].

${ }^{4}$ H. H. Rennhard, E. Heilbronner, and A. Eschenmoser, Chem. Ind. London 1955, 415.

5 H. H. Rennhard, G. di Modica, W. Simon, E. Heilbronner, and A. Eschenmoser, Helv. Chim. Acta 40, 957 [1957].

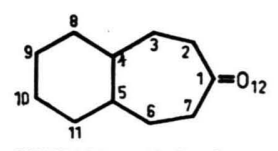

4,5-BENZOTROPONE (I)<smiles>O[C@@]12CCCCCC1CCCC2</smiles>

2,3 - BENZOTROPONE (II)<smiles>O=C1CCCC2CCCCC2C1</smiles>

3,4-BENZOTROPONE (III)

- G. L. Buchanan and D. R. Lockhart, Chem. Ind. London 1958, 1391.

7 T.Gäumans, R.W.Schmid, and E. Heilbronner, Helv. Chim. Acta 39, 1985 [1956].

8 R. W. Schmid and E. Heilbronner, Helv. Chim. Acta 40, 950 [1957].

9 G. L. Buchanan and D. R. Lockhart, J. Chem. Soc. 1959, 3586 . 
ing the positions of electrophilic, radical, or nucleophilic attack. In doing this we examine the properties of the molecular orbitals of the initial compounds or in other words we have followed the isolated-molecule approximation ${ }^{10}$. In this approximation we can expect a correlation between the electron density and the attacking charged species. Since the radical species are neutral the correlation with the free valence proved to be quite successful. It is also possible to correlate the reactivity of the bond with the bond order value, and predict the most reactive bonds.

We have therefore applied the molecular orbital theory in the frame-work of the Hückel method ${ }^{11, *}$ in order to calculate the $\pi$-bond orders (Table 1 ), the $\pi$-electron densities, the free valence indices, the superdelocalizabilities, and the frontier electron densities (Table 2). The predictions of reactivity are given in Table 3. These predictions are based on three groups of quantities: 1 . the $\pi$-charge densities, the $\pi$-bond

\begin{tabular}{rrrccc}
\hline & \multicolumn{2}{c}{ II } & \multicolumn{2}{c}{ III } \\
Bond & $p_{i j}$ & Bond & $p_{i j}$ & Bond & $p_{i j}$ \\
\hline $1-2$ & 0.371 & $1-2$ & 0.335 & $1-2$ & 0.426 \\
$2-3$ & 0.821 & $1-7$ & 0.380 & $1-7$ & 0.408 \\
$3-4$ & 0.466 & $2-3$ & 0.560 & $2-3$ & 0.659 \\
$4-5$ & 0.539 & $2-8$ & 0.631 & $3-4$ & 0.452 \\
$4-8$ & 0.596 & $3-4$ & 0.476 & $3-8$ & 0.516 \\
$8-9$ & 0.690 & $3-11$ & 0.587 & $4-5$ & 0.615 \\
$9-10$ & 0.633 & $4-5$ & 0.768 & $4-11$ & 0.534 \\
$1-12$ & 0.799 & $5-6$ & 0.526 & $5-6$ & 0.602 \\
& & $6-7$ & 0.793 & $6-7$ & 0.737 \\
& & $8-9$ & 0.679 & $8-9$ & 0.747 \\
& & $9-10$ & 0.638 & $9-10$ & 0.573 \\
& & $10-11$ & 0.694 & $10-11$ & 0.740 \\
& & $1-12$ & 0.808 & $1-12$ & 0.756 \\
\hline
\end{tabular}

Table 1 . $\pi$-bond orders.

orders, and the free valence indices; 2 . the superdelocalizabilities; and 3 . the frontier electron densities $* *$.

\begin{tabular}{|c|c|c|c|c|c|c|c|c|c|}
\hline Compound & Position & $q$ & $F$ & $S_{\mathrm{e}}$ & $S_{\mathrm{r}}$ & $S_{\mathrm{n}}$ & $D_{\mathrm{e}}$ & $D_{\mathrm{r}}$ & $D_{\mathrm{n}}$ \\
\hline \multirow[t]{7}{*}{ I } & 1 & 0.796 & 0.191 & 0.296 & 0.507 & 0.718 & 0.023 & 0.012 & 0.000 \\
\hline & 2 & 1.015 & 0.540 & 1.104 & 0.865 & 0.625 & 0.397 & 0.431 & 0.464 \\
\hline & 3 & 0.919 & 0.445 & 0.746 & 0.920 & 1.095 & 0.073 & 0.108 & 0.143 \\
\hline & 4 & 0.982 & 0.131 & 0.749 & 0.655 & 0.562 & 0.202 & 0.212 & 0.222 \\
\hline & 8 & 0.987 & 0.446 & 0.901 & 0.947 & 0.993 & 0.015 & 0.022 & 0.028 \\
\hline & 9 & 0.985 & 0.409 & 0.843 & 0.799 & 0.755 & 0.136 & 0.139 & 0.143 \\
\hline & 12 & 1.429 & 0.933 & 0.903 & 0.457 & 0.012 & 0.332 & 0.166 & 0.000 \\
\hline \multirow[t]{12}{*}{ II } & 1 & 0.791 & 0.210 & 0.299 & 0.508 & 0.718 & 0.021 & 0.026 & 0.030 \\
\hline & 2 & 1.002 & 0.207 & 0.840 & 0.820 & 0.800 & 0.087 & 0.099 & 0.111 \\
\hline & 3 & 0.974 & 0.111 & 0.682 & 0.685 & 0.689 & 0.060 & 0.045 & 0.030 \\
\hline & 4 & 0.942 & 0.488 & 0.955 & 0.892 & 0.829 & 0.328 & 0.397 & 0.467 \\
\hline & 5 & 0.985 & 0.438 & 0.974 & 0.745 & 0.516 & 0.322 & 0.274 & 0.226 \\
\hline & 6 & 0.924 & 0.413 & 0.713 & 0.884 & 1.056 & 0.064 & 0.144 & 0.225 \\
\hline & 7 & 1.025 & 0.559 & 1.242 & 0.851 & 0.460 & 0.504 & 0.486 & 0.468 \\
\hline & 8 & 0.977 & 0.423 & 0.830 & 0.841 & 0.853 & 0.051 & 0.045 & 0.040 \\
\hline & 9 & 0.989 & 0.415 & 0.888 & 0.787 & 0.686 & 0.178 & 0.178 & 0.177 \\
\hline & 10 & 0.980 & 0.400 & 0.789 & 0.846 & 0.903 & 0.000 & 0.000 & 0.000 \\
\hline & 11 & 0.990 & 0.451 & 0.944 & 0.848 & 0.752 & 0.173 & 0.178 & 0.183 \\
\hline & 12 & 1.422 & 0.925 & 0.893 & 0.508 & 0.123 & 0.210 & 0.127 & 0.044 \\
\hline \multirow[t]{12}{*}{ III } & 1 & 0.823 & 0.143 & 0.384 & 0.459 & 0.533 & 0.049 & 0.025 & 0.000 \\
\hline & 2 & 0.980 & 0.647 & 1.505 & 1.459 & 1.412 & 0.476 & 0.504 & 0.531 \\
\hline & 3 & 0.957 & 0.106 & 0.618 & 0.799 & 0.881 & 0.003 & 0.021 & 0.038 \\
\hline & 4 & 0.972 & 0.131 & 0.726 & 0.810 & 0.893 & 0.042 & 0.057 & 0.071 \\
\hline & 5 & 0.922 & 0.516 & 1.078 & 1.273 & 1.468 & 0.281 & 0.338 & 0.394 \\
\hline & 6 & 0.948 & 0.394 & 0.713 & 0.849 & 0.984 & 0.000 & 0.008 & 0.015 \\
\hline & 7 & 0.961 & 0.588 & 1.213 & 1.413 & 1.612 & 0.278 & 0.354 & 0.430 \\
\hline & 8 & 0.997 & 0.469 & 1.106 & 0.978 & 0.849 & 0.213 & 0.194 & 0.175 \\
\hline & 9 & 0.977 & 0.412 & 0.849 & 0.911 & 0.974 & 0.059 & 0.072 & 0.085 \\
\hline & 10 & 0.984 & 0.419 & 0.932 & 0.904 & 0.877 & 0.132 & 0.128 & 0.123 \\
\hline & 11 & 0.988 & 0.458 & 1.016 & 0.963 & 0.910 & 0.153 & 0.145 & 0.138 \\
\hline & 12 & 1.492 & 0.976 & 1.261 & 0.418 & 0.425 & 0.313 & 0.157 & 0.002 \\
\hline
\end{tabular}

Table 2. Reactivity indices. $q$ is the $\pi$-electron density, $F$ the free valence, $S$ the superdelocalisability, and $D$ the frontier electron density (e: electrophilic, $\mathrm{r}$ : radical, $\mathrm{n}$ : nucleophilic).

10 J. N. Murrell, S. F. A. Kettre, and J. M. Tedder, Valence Theory, Wiley, London 1965, p. 317.

11 E. HücKel, Z. Physik 70, 204 [1931].

* The assumption was made that all three investigated molecules are planar. The following empirical parameters were used in the calculations: $a_{0}=a_{\mathrm{c}}+1.20 \beta_{\mathrm{cc}}, a_{1}=a_{\mathrm{c}}-0.040$ $\beta_{\mathrm{cc}}, a_{2}=a_{\mathrm{c}}$, and $\beta_{\mathrm{c} 0}=2.00 \beta_{\mathrm{cc}}$, respectively.
** Although there are no experimental data for 3,4-benzotropone, we have for the sake of completness included in the Tables its theoretical results. 


\begin{tabular}{cllll}
\hline \multirow{2}{*}{ Compound } & electrophilic & nucleophilic & radical & addition \\
& $2,7>8,11 \mathrm{a}$ & $3,6>9,10 \mathrm{a}$ & $2,7>8,11 \mathrm{a}$ & $2-3,6-7 \mathrm{a}$ \\
I & $2,7>8,11 \mathrm{~b}$ & $3,6>8,11 \mathrm{~b}$ & $8,11>3,6 \mathrm{~b}$ & \\
& $2,7>9,10 \mathrm{c}$ & & \\
II & $7>11>9 \mathrm{a}$ & $6>4>8 \mathrm{a}$ & $7>11>4 \mathrm{a}$ & $6-7>4-5 \mathrm{a}$ \\
& $7>11>5 \mathrm{~b}$ & $6>10>8 \mathrm{~b}$ & $4>6>7 \mathrm{~b}$ & \\
& $7>4>5 \mathrm{c}$ & & & \\
III & $8>11>10 \mathrm{a}$ & $5>6>7 \mathrm{a}$ & $2>7>5 \mathrm{a}$ & $8-3>6-7 \mathrm{a}$ \\
& $2>7>8 \mathrm{~b}$ & $7>5>2 \mathrm{~b}$ & $2>7>5 \mathrm{~b}$ &
\end{tabular}

Table 3. The prediction of reactivity. a Prediction based on the charge densities, bond orders, and free valence indices; $\mathrm{b}$ prediction based on the superdelocalisabilities; $\mathrm{c}$ prediction based on the frontier electron densities.

Positions 2 and 7 in 4,5-benzotropone (2-chloro-4,5benzotropone ${ }^{12}$, 2 -acetyl-4,5-benzotropone ${ }^{13}, 2,7$-dibenzoyl-4,5-benzotropone ${ }^{14}$ ) and position 7 (or 5) in 2,3benzotropone (7-chloro-2,3-benzotropone ${ }^{4}, 5,7$-dibromo2,3-benzotropone ${ }^{9}$, 5,7-dinitro-2,3-benzotropone ${ }^{9}$ ) are the most reactive sites for electrophilic reagents. Positions 3 and 6 in 4,5-benzotropone and position 6 (or 4) in 2,3-benzotropone (4-hydroxy-2,3-benzotropone ${ }^{15}$ ) are the possible sites for nucleophilic attack. Positions 2 and 7 (or 8 and 11) in 4,5-benzotropone (2,7-dimethyl-4,5-benzotropone ${ }^{7,8,16-19}, 2,7$-diethyl-4,5-benzotropone $^{16}, 2$-methyl-4,5-benzotropone ${ }^{7,20-22}, 2,7$-dialkyl-

12 W. E. Parham, D. A. Bolon, and E. E. Schweizer, J. Am. Chem. Soc. 83, 603 [1961].

13 W. Davey and H. Gottrried, J. Org. Chem. 26, 3699 [1961].

14 M. Laćan and R. Kućan, Croat. Chem. Acta 35, 141 [1963].

15 G. L. Buchanan and J. K. Sutherland, J. Chem. Soc. 1956, 2620.

16 H. Götz, E. Heilbronner, A. R. Katritzky, and R. A. Jones, Helv. Chim. Acta 44, 387 [1961].

17 E. Kloster-Jensen, N. Tarköy, A. Eschenmoser, and E. HeiLBronner, Helv. Chim. Acta 39, 786 [1956]. 4,5-benzotropone ${ }^{21}$ ) and position 7 (or 4) in 2,3-benzotropone (5,7-dialkyl-2,3-benzotropone ${ }^{21}$ ) are the most reactive positions for radical attack. The most reactive bonds for addition reactions in all of the three investigated compounds are the bonds next to that carbon atom in the tropone ring which is bonded to oxygen.

Finally we want to point out that the coincidence of these predictions based on three different groups of quantities is not surprising since all these are derived from the Hückel coefficients and because of that they are not independent quantities and therefore all lead to similar predictions for the positions of attack.

18 J. Breeze Bentley, K. B. Everard, R. J. B. Marsden, and L. E. Sutton, J. Chem. Soc. 1949, 2957.

19 E. Weltin, E. Heilbronner, and H. Labhart, Helv. Chim. Acta 46, 2041 [1963].

20 P. Rona, J. Chem. Soc. 1962, 3629.

21 D. Meuche, H. Strauss, and E. Heilbronner, Helv. Chim. Acta 41, 2220 [1958].

22 M. E. Vol'pin and A. F. Plate, Dokl. Akad. Nauk SSSR 70, 843 [1950]. 